\title{
Symposium 8
}

\section{Cultured Vascular Cells and Atherogenesis}

\section{Immortalization of Human Endothelial Cells*}

\author{
Kimiko TaKahashi**, Yoshio SaWASAKI** and Tamotsu Goto**
}

During the development of cultivation technique of venous endothelial cells from more than 600 human umbilical cords in number, a cell line growing to cobblestone monolayer has been estab-

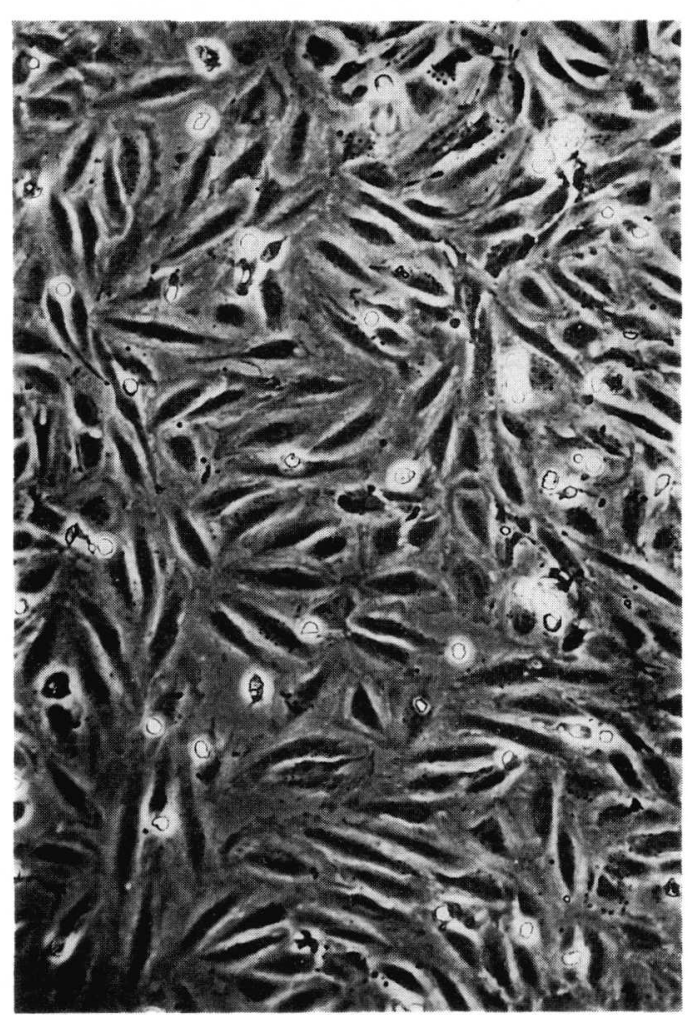

HUVEC

$\times 245$ lished and maintained for more than 3 years (166 generations) (Fig. 1). This strain designated ECV304 was characterized by a high proliferative potential in $10 \%$ FBS-containing M199 without

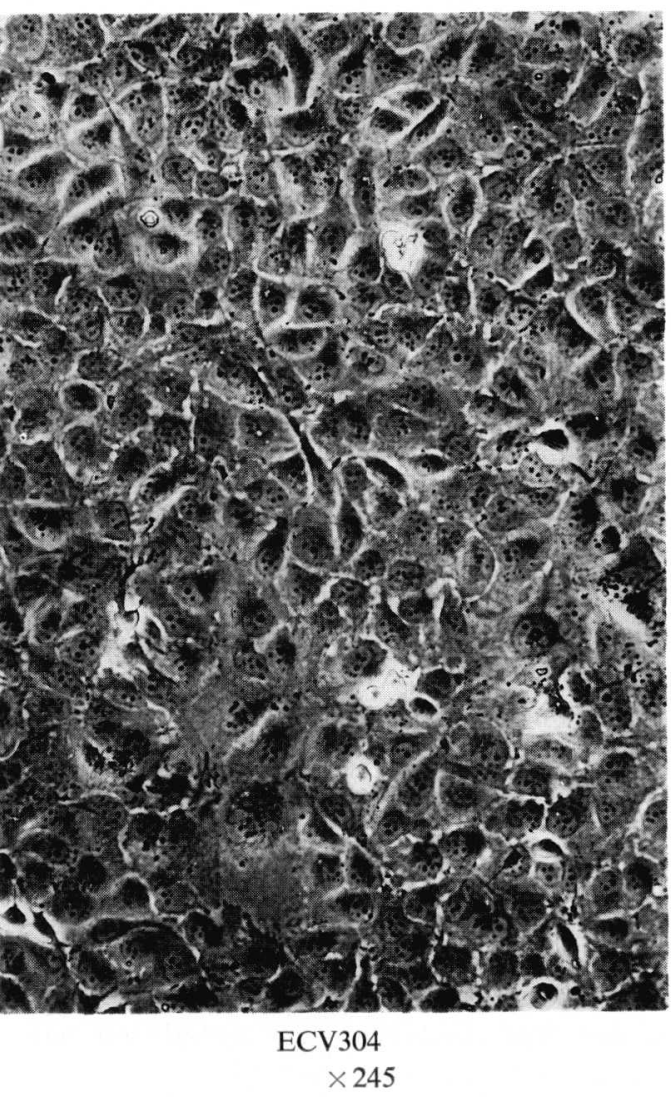

Fig. 1 Morphology of monolayers.

\footnotetext{
* This paper was presented at the winter meeting of the Japan Atherosclerosis Society in Japan in December 1987

** Department of Biochemistry, National Defense Medical College
} 


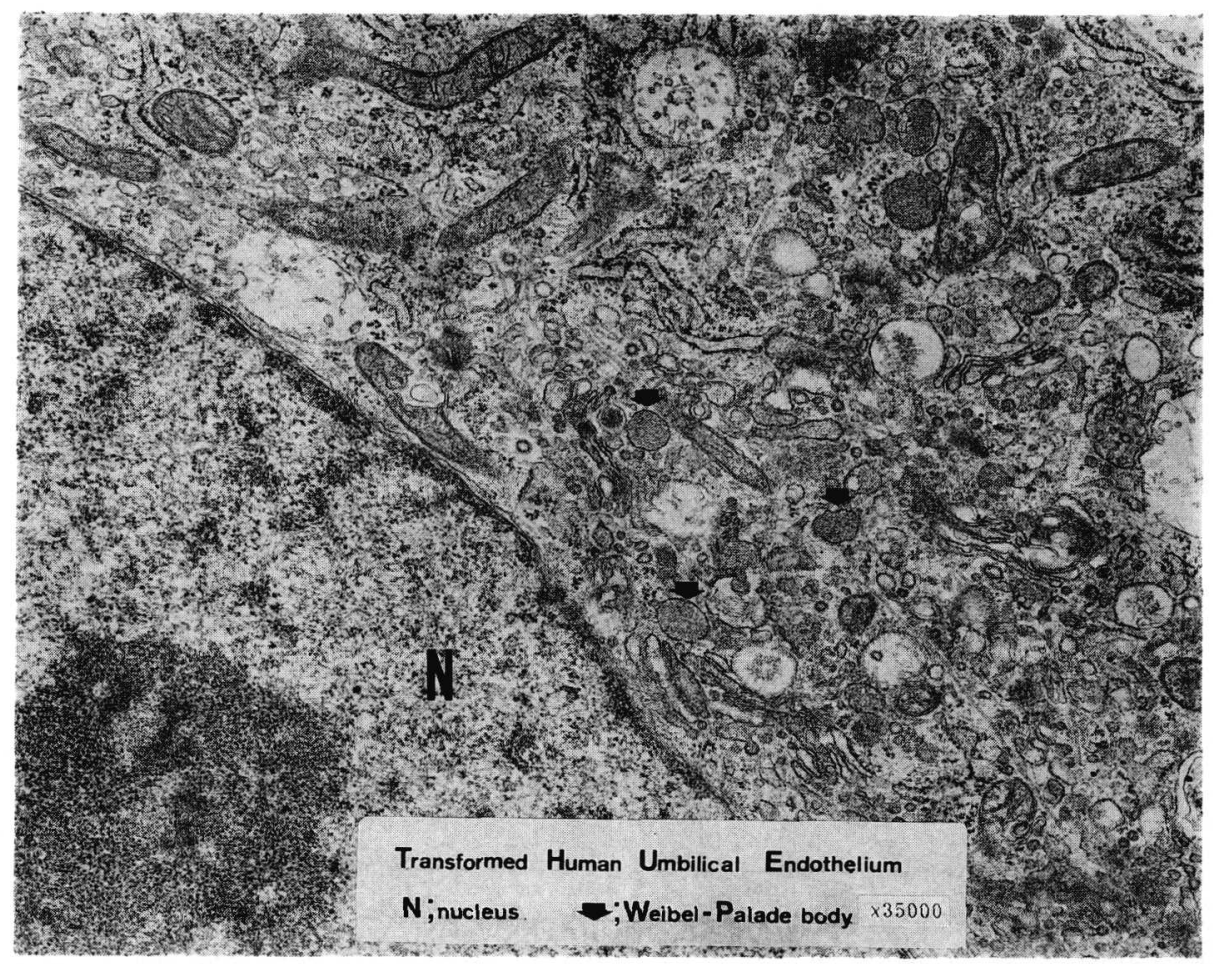

Fig. 2

any specific growth factor supplement, an anchorage dependency with contact inhibition, a human chromosomal constitution with a high trisomic karyotype (mode 80 ), nude mouse tumorigenicity and induction of angiogenesis in rabbit cornea test. Although one of the prominent endothelium markers-Factor VIII related antigen ${ }^{1)}$ - was not detectable, the presence of angiotensin converting enzyme $^{2)}$ and Weibel-Palade bodies $^{3}$ - characteristic of cytoplasmic organelle in endothelium(Fig. 2), positive immunocytochemirtry for the lectin Ulex europaeus $\mathrm{I}^{4}$, negative staining for alkaline and acid phosphatase as well as several monoclonal anti-human monocyte antibodies, in addition, lack of the mesothelial and epithelial marker keratin ${ }^{5)}$, suggest that ECV304 has been originated from umbilical vein endothelial cells by spontaneous transformation but from neither histiocytes nor mesothelial cells. Ultrastructurally, none of the virus-like particles has been detected intracellularlly. Human cell lines have been known to exhibit very low frequencies of spontaneous transformation. However, Factor VIII related antigen-poor variant endothelium has been reported to appear not only in the atherosclerotic but also in the healthy arterial endothelial cells in culture $^{6)}$. Monoclonal theory assumes that each atherosclerotic plaque is derived from a single mutationally transformed smooth muscle cell ${ }^{7}$. This work is a report on one case of a phenotypic alteration of normal venous endothelial cells of human origin in vitro and the generation of a transformant with indefinite life spans.

\section{References}

1) Mukai, K., Rosai, J. and Burgdorf, W. H. C.: Localization of Factor VIII-related antigen in vascular endothelial cells using an immunopreoxidase method. Am. J. Surg. Pathol., 4: 273-276 (1980).

2) Hayes, L. W., Goguen, C. A., Ching, S. F. and Slakey, L. L.: Angiotensin converting enzyme: Accumulation in medium from cultured endothelial cells. Biochem. Biophys. Res. Commun., 82: 1147 1153 (1978).

3) Weibel, E. R. and Palade, G. E.: New cytoplasmic components in arterial endothelia. J. Cell Biol., 23: 101-112 (1964).

4) Holthöfer, H., Virtanen, I., Kariniemi, A.-L., Hormia, M., Linder, E. and Miettinen, A.: Ulex europaeus I lectin as a marker for vascular endo- 


\section{Immortalization of Human Endothelial Cells}

thelium in human tissues. Lab. Invest., 47: 60-66 (1982).

5) Connell, N. D. and Rheinwald, J. G.: Regulation of the cytoskeleton in mesothelial cells: Reversible loss of keratin and increase in vimentin during rapid growth in culture. Cell, 34: 245-253 (1983).

6) Tokunaga, O. and Watanabe, T.: Atherosclerosis and endothelium Part 1. A simple method of endothelial cell culture from human atherosclerotic aorta. Acta Pathol. Jpn., 37: 527-536 (1987).

7) Benditt, E. P. and Benditt, J. M.: Evidence for a monoclonal origin of human atherosclerotic plaques. Proc. Natl. Acad. Sci. U.S.A., 70: 17531756 (1973). 